\title{
Healthy and Open Phase PMaSynRM Model Based on Virtual Reluctance Concept
}

\author{
T.D. Michalski, Member, IEEE, J.L. Romeral, Member, IEEE, \\ G. Mino-Aguilar, Member, IEEE
}

\begin{abstract}
The trend in the industrial power electronics electrical drives is to reach high power density and high efficiency in variable load conditions at cost-effective unwasteful designs. Currently, motors with permanent magnets (such as IPMSM and PMaSynRM) are of great interest because of compactness, low losses, and high torque capability. The performance of a drive system can be predicted with a motor electromagnetic authentic nonlinear model. In this paper, a novel, fast, and precise motor model of PMaSynRM based on virtual reluctance (VR) is proposed. It takes into account the cross saturation, winding distribution, space harmonics, slotting effect, and stepped skewing. The virtual reluctances are identified by finite element analysis (FEA) and implemented in the timestepping simulation. The flux inversion is not required. The proposed concept is useful for the rotating field or phase quantities (for open phase simulation). The model is also discretized for SiL and HiL applications. Finally, the validation in FEA and experimental setup was performed.
\end{abstract}

Index Terms-Permanent Assisted Synchronous Reluctance Motor (PMaSynRM), Interior Permanent Magnet Synchronous Motor (IPMSM), cross saturation, space harmonics, stepped skewing.

\section{INTRODUCTION}

$\mathrm{T}$ $\mathrm{HE}$ trend in the industrial drive applications is to reach major power and torque densities with high efficiency, and reliability [1]. These advantages are offered by the Interior Permanent Magnet Synchronous Motor (PMSM) which is widely realized in drive applications ranging from low to high power such as in electric vehicles, wind turbines, household appliances, and other industrial usages [2]-[4]. In low-power battery-powered equipment, e.g. power tools [5], the torque generation may be limited due to low ambient temperature, too high battery internal impedance, and available current limit that inhibits startup of the increasing load profile (for instance during compression). High performance is also desired in drives with the reduced number of sensors or when feedback

Manuscript received Month $x x, 2 x x x$; revised Month $x x$, xxxx; accepted Month $x, x x x x$. This work was supported in part by the ... Department of $x x x$ under Grant (sponsor and financial support acknowledgment goes here).

(Authors' names and affiliation) F. A. Author1 and S. B. Author2 are with the xxx Department, University of Xxx, City, Zip code, Postcode, measurement is incomplete [6], like in continuous position reconstruction from rotor sectors captured by the hall sensors. These kinds of applications require prediction of the motor behavior for drive optimization.

In medium power, Permanent Assisted Synchronous Reluctance Motor (PMaSynRM) has gained attention as a costeffective alternative for IPMSM construction [7]. This is achieved by the replacement of the scarce rare earth magnets by widely available magnets based on the ferrite composites. The PMaSynRM reaches a wide speed range and high performance close to IPMSM and due to its resource footprint, it becomes competitive in many applications [8], [9].

High power propulsion systems enforced the employment of multi-phase motors. First trials were proposed in the 60s with a five-phase induction motor [10]. On the power converter side, the main benefit is the reduction of the maximum rating of the electronic switches as a result of power division between more than three phases. On the motor side, lower torque ripple amplitude and higher frequency were observed. The advantages of multi-phase motor suit well aerospace and ship propulsion applications [11]. Moreover, the fault-tolerant capability leverages the potential of multi-phase motors since they can provide reliable quality torque when one or more phases is out of order [12].

Every electric motor including PMaSynRM and IPMSM motor is a highly nonlinear system. Inherently, nonlinearities originate from the mutual magnetic coupling between phase windings that leads to back-EMF generation. This is contemplated in the conventional model with inductances corresponding to $d$ and $q$ axes. However, the soft magnetic core saturates with increased current flow from each axis. These phenomena degrade the accuracy of model-based control trajectories for maximum torque per ampere (MTPA) and flux weakening (FW) [13]. A similar cross saturation effect exists in multi-phase machines in which the multiple $d q$ reference frames are bound to first and consecutive harmonics. Besides, the discrete coil distribution and non-uniform field projected by

Country, on leave from the National Institute for xxx, City, Zip code, Country (e-mail: author@domain.com).

T. C. Author3 is with the National Institute of xxx, City, Zip code, Postcode, Country (corresponding author to provide phone: $x x x-x x x-$ xxxx; fax: xxx-xxx-xxxx; e-mail: author@ domain.gov). 
permanent magnets contribute to space harmonics and increase distortions in the induced voltages. Additionally, saliency and magnetic co-energy variation result in extra reluctant torque components.

Undoubtedly, finite element analysis (FEA) is a very precise tool to model motor behavior, being in the same tame computationally very heavy. Therefore, for control design and rapid prototyping, a fast mathematical model is essential. Neglecting saturation and assuming the sinusoidal nature of the air-gap field the motor can be modeled in the stator phase quantities or rotating $d q$ rotor reference frame or frames when concerning multi-phase machinery. It was possible to include saturation and field harmonics by the projection of the inverted flux maps into $d q$ and $a b c$ models of three-phase IPMSM [14][18]. However, the inversion of the flux linkage look-up table (LUT) becomes cumbersome with the higher number of phases [19]. The residual flux implies errors in the current calculation jeopardizing accuracy in the time-stepping simulation.

This paper presents a new method for reliable and computation effective modeling of five-phase PMaSynRM taking into account cross saturation, field harmonics, and stepped skewing based on virtual reluctances (VRs) identified by FEA. The model is implemented in the $d q$ rotating fields or directly in the natural abcde phase quantities to predict motor behavior in open phase scenarios. Then, the model is discretized and loaded in a SIL platform. For the healthy and fault-tolerant drive development and optimization, the performance prediction is crucial and the proposed model offers a compromise between reliability and computational time.

\section{REVIEW OF CONVENTIONAL MODELS}

The models that include cross saturation and voltage distortions depart from the conventional models with constant parameters, well known in the literature.

\section{A. Model in stator phase quantities}

The time-domain matrix form of the stator voltage equation of the five-phase PMaSynRM is given as follow:

$$
\begin{aligned}
& \mathbf{U}=\mathbf{R}_{\mathrm{s}} \mathbf{i}+\frac{d \boldsymbol{\psi}}{d t} \\
& \boldsymbol{\psi}=\mathbf{L} \mathbf{i}+\boldsymbol{\psi}_{\mathbf{P M}}
\end{aligned}
$$

where $\mathbf{U}$ stands for the stator voltage vector, i for stator current vector and $\boldsymbol{\psi}$ denotes stator flux linkage vector, which is calculated from the inductance matrix $\mathbf{L}$ and permanent magnet flux vector $\boldsymbol{\psi}_{\mathbf{P M}}$. Considering sinusoidal first and third harmonic and no saturation, $\mathbf{L}$ contains 15 elements per harmonic and is obtained from the self and mutual inductances that contain DC and variable components. This is already a quite complex system although it does not comprise saturations nor space harmonics. To include these effects, the elements of the flux linkage vector $\boldsymbol{\psi}$ in (1) can be written as functions:

$$
\psi_{x}=f_{x} i_{a}, i_{b}, i_{c}, i_{d}, i_{e}, \theta_{r}
$$

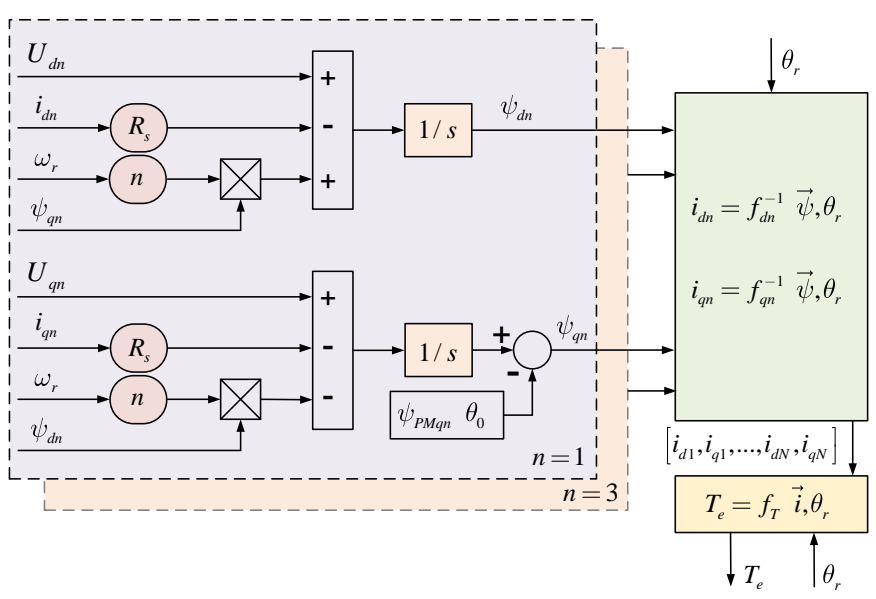

Fig. 1. Five phase PMaSynRM classic inverted flux map model in field rotating quantities.

where $x$ indicates one of the five phases. Thus, flux linkages are functions of all phase current and the rotor position $\theta_{r}$. Therefore, they contain geometry and saturation-induced harmonics. These functions are computed by the FEA static analysis and stored as 6D LUTs. In the time-stepping simulation, the flux linkage vector is determined from the integration:

$$
\boldsymbol{\psi}=\int \mathbf{U}-\mathbf{R}_{\mathbf{s}} \mathbf{i} d t+\boldsymbol{\psi} \theta_{0}
$$

and the elements of the current vector $\mathbf{i}$ are obtained from the inversion of the flux maps:

$$
i_{x}=f_{x}^{-1} \psi_{a}, \psi_{b}, \psi_{c}, \psi_{d}, \psi_{e}, \theta_{r}
$$

where $x$ denotes one of the phases. The pre-calculation of the current maps is time-consuming and prone to errors of the iterative search and residual flux minimization. Therefore, the stability of the model is affected and it is especially critical with high dimension problems.

\section{B. Model in rotating field quantities}

Conceptually, the flux map extraction and inversion are also applicable to PMaSynRM models built in $d q$ rotating reference frames [20], [21]. The set of equations is shown in the following:

$$
\begin{gathered}
U_{d n}=R_{s} i_{d n}+\frac{d \psi_{d n}}{d t}-n \omega_{r} \psi_{q n} \\
U_{q n}=R_{s} i_{q n}+\frac{d \psi_{q n}}{d t}+n \omega_{r} \psi_{d n} \\
\psi_{d n}=f_{d n} \quad i_{d 1}, i_{q 1}, i_{d 3}, i_{q 3}, \theta_{r} \\
\psi_{q n}=f_{q n} \quad i_{d 1}, i_{q 1}, i_{d 3}, i_{q 3}, \theta_{r} \\
T_{e}=f_{T} \quad i_{d 1}, i_{q 1}, i_{d 3}, i_{q 3}, \theta_{r}
\end{gathered}
$$




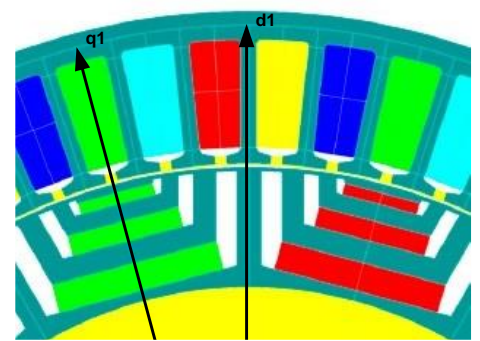

Fig. 2. Cross section of the five-phase PMaSynRM prototype.

TABLE I

PROTOTYPE MOTOR SPECIFICATION

\begin{tabular}{lll}
\hline \hline Quantity & \multicolumn{1}{c}{ Unit } & Value \\
\hline Number of phases & - & 5 \\
Rated torque & $\mathrm{Nm}$ & 6.8 \\
Base speed & $\mathrm{r} / \mathrm{min}$ & 5000 \\
Rated power & $\mathrm{kW}$ & 3.5 \\
Peak current & $\mathrm{A}$ & 10 \\
Rated current & $\mathrm{A}$ & 4.5 \\
Stator resistance & $\Omega$ & 2.2 \\
Number of pole pairs & - & 6 \\
Number of slots & - & 60 \\
Active stack length & $\mathrm{mm}$ & 26 \\
Stator outer diameter & $\mathrm{mm}$ & 148 \\
Rotor outer diameter & $\mathrm{mm}$ & 114 \\
Airgap length & $\mathrm{mm}$ & 6 \\
Number of skew sections & - & 2 \\
Skew angle & $\circ$ & 6 \\
\hline \hline
\end{tabular}

where $n$ denotes first $(n=l)$ or third $(n=3)$ harmonic space, $d$ and $q$ respective axes quantities. Flux linkages $\psi_{d n}, \psi_{q n}$, and torque $T_{e}$ are functions of all $d 1, q 1, d 3, q 3$ currents and the rotor position obtained from FEA. Then, the inversions to obtain current maps are computed such as:

$$
\begin{aligned}
& i_{d n}=f_{d n}^{-1} \quad \psi_{d 1}, \psi_{q 1}, \psi_{d 3}, \psi_{q 3}, \theta_{r} \\
& i_{q n}=f_{q n}^{-1} \psi_{d 1}, \psi_{q 1}, \psi_{d 3}, \psi_{q 3}, \theta_{r}
\end{aligned}
$$

The model is depicted in Fig. 1. The main drawback is the existence and accuracy of the 5D flux map inversion. It is valid for the balanced system, does not account for axial asymmetry, and cannot predict the motor behavior in the open phase fault occurrence.

\section{Proposed PMaSynRM Model}

The model described hereafter is developed for a prototype 60slot, 6-pole five-phase PMaSynRM with star-connected winding to demonstrate its effectiveness. However, it can be applied to any synchronous motor type. The model comprises all of the aforementioned nonlinearities and some simplifying assumptions are considered. The eddy currents and hysteresis losses in the soft magnetic parts are neglected as well as the eddy currents in magnets. In this section, the motor is considered to be axially symmetric.

\section{A. Virtual reluctance concept}

The conventional flux map inversion can be avoided with the introduction of the virtual reluctance concept. Magnetic

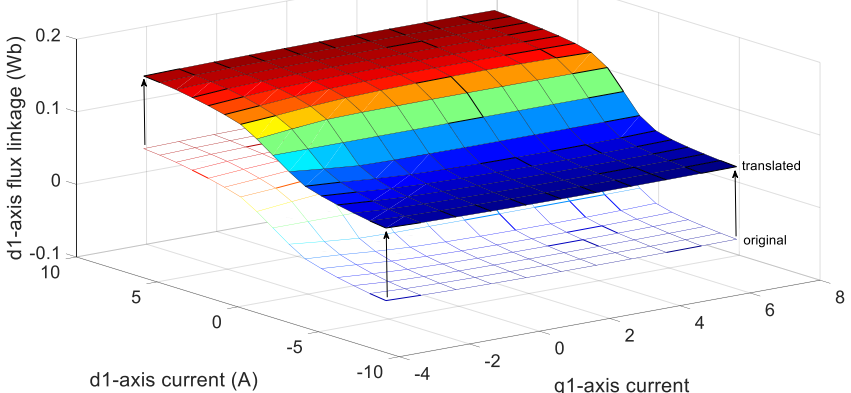

Fig. 3. Original and translated $d 1$ flux linkage map at $i_{d 3}=0 A, i_{q 3}=O A$ and rotor angle $=0$ rad.

reluctance $\Re$ is defined as:

$$
\Re=\frac{F}{\psi}
$$

where $F$ is the magnetomotive force (MMF) and $\psi$ is the magnetic flux. In general, virtual reluctance will be defined as:

$$
\Re=\frac{i+k_{1}}{\psi+k_{2}}
$$

where $k_{1}, k_{2}$ are coefficients of vector translation. In this sense, the virtual reluctance can be calculated for any fluxcurrent pair associated with a rotating axis or phase quantity.

\section{B. Implementation in rotating frame}

The flux map LUT was obtained for the five-phase PMaSynRM motor performing a multi-static FEA sweep. In the next step, the apparent virtual reluctances are calculated as follows:

$$
\begin{aligned}
\Re_{d n} & =\frac{i_{d n}+k_{1 d n}}{f_{d n} i_{d 1}, i_{q 1}, i_{d 3}, i_{q 3}, \theta_{r}+k_{2 d n}} \\
\Re_{q n} & =\frac{i_{q n}+k_{1 q n}}{f_{q n} i_{d 1}, i_{q 1}, i_{d 3}, i_{q 3}, \theta_{r}+k_{2 q n}}
\end{aligned}
$$

where $i_{d n}$ and $i_{q n}$ are always currents of the corresponding harmonic in one axis only while the flux linkage functions $f_{d n}$ and $f_{q n}$ depend on currents from all axes. In Fig. 6 the section of the flux linkage map is depicted together with its translation along the $z$-axis. The idea is to keep the translated flux points always positive to avoid singularities. Hence, the coefficient $k_{2}$ needs to be at least higher than the absolute of the minimum value of the whole original flux map. Further, to guarantee numerical stability in the time-stepping model, the apparent virtual reluctances must always be positive. This is achieved by the adjustment of the coefficient $k_{1}$ to be at least higher than the absolute of the lowest current coordinate of the flux linkage map. A 2D segment of the $d l$ axis virtual 


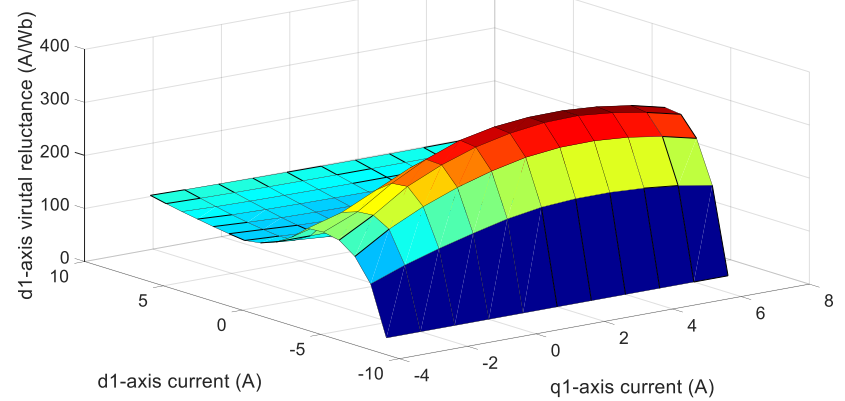

Fig. 4. Virtual reluctance map of $d 1$ axis at $i_{d 3}=0 A, i_{q 3}=0 A$ and rotor angle $=0$ rad.

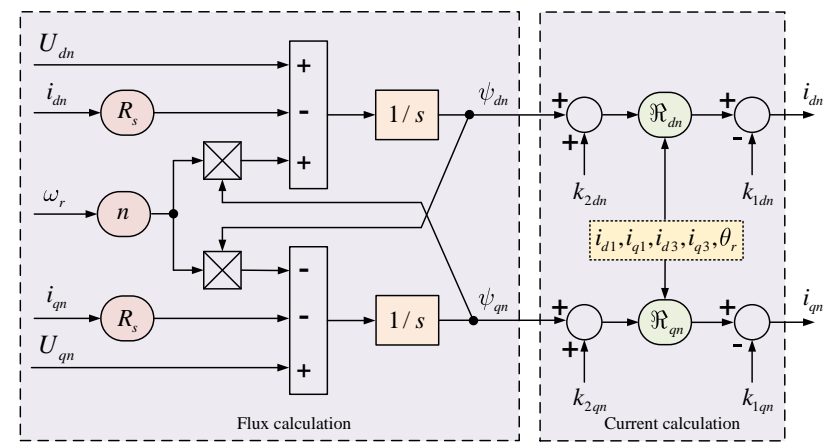

Fig. 5. Schematic of the proposed five-phase PMaSynRM model.

reluctance map is shown in Fig. 4. The pre-calculation of VRs from the flux maps takes few seconds.

Next the VR map is introduced in the model to calculate currents from the flux linkages:

$$
\begin{aligned}
& i_{d n}=\left[\int U_{d n}-R_{s} i_{d n}+n \omega_{r} \psi_{q n} d t+k_{2 d n}\right] \cdot \Re_{d n}-k_{1 d n} \\
& i_{q n}=\left[\int U_{q n}-R_{s} i_{q n}-n \omega_{r} \psi_{d n} d t+k_{2 q n}\right] \cdot \Re_{q n}-k_{1 q n}
\end{aligned}
$$

The schematic of the electromagnetic model is shown in Fig. 5. Once currents are evaluated, the torque is interpolated from the LUT as in (8).

\section{Implementation is stationary frame}

Implementation of the VRs in the natural phase abcde quantities is analogical to (12) and (13). The virtual reluctance of each phase is calculated as follows:

$$
\Re_{x}=\frac{i_{x}+k_{1 x}}{f_{x} i_{a}, i_{b}, i_{c}, i_{d}, i_{e}, \theta_{r}+k_{2 x}}
$$

where $f_{x}$ defines the function of the flux map of any phase and it depends on the currents from all phases and the rotor position. This map and the phase coordinate vector $i_{x}$ are translated during pre-calculation by units defined in coefficients $k_{2 x}$ and $k_{1 x}$, and the VR is calculated. Then, in the model in the first step, the $k_{2 x}$ is coupled and $k_{1 x}$ decoupled in the current calculation:

$$
i_{x}=\left[\int U_{x}-R_{s} i_{x} d t+k_{2 x}\right] \cdot \Re_{x}-k_{1 x}
$$

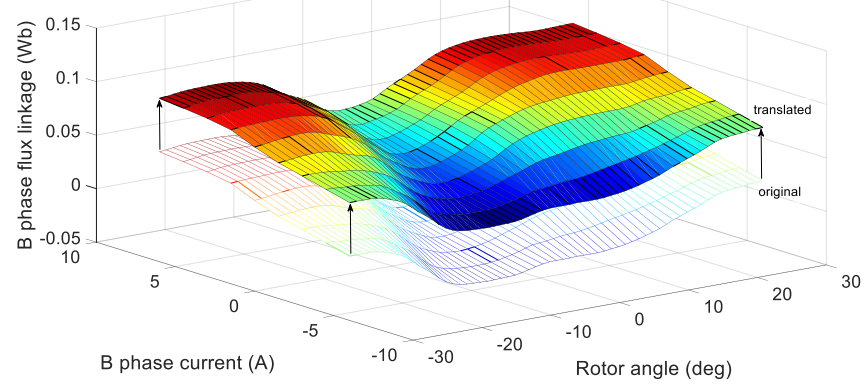

Fig. 6. Original and translated a-phase flux linkage map at $i_{a}=i_{c}=i_{d}=$ $i_{e}=-3 A$.

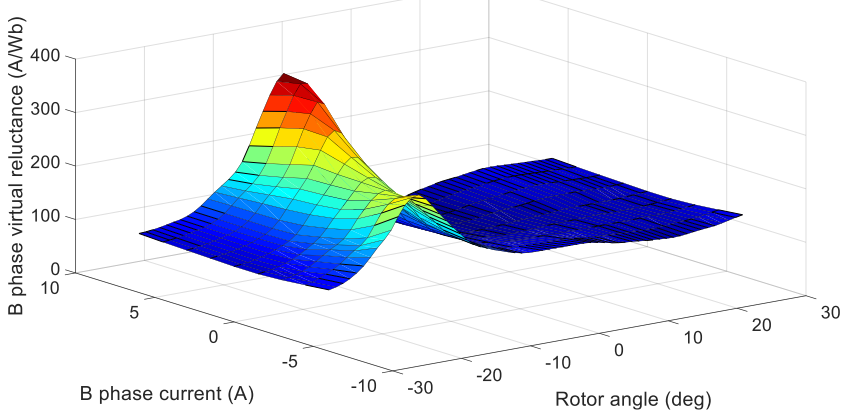

Fig. 7. Virtual reluctance of the a-phase at $i_{a}=i_{c}=i_{d}=i_{e}=-3 \mathrm{~A}$.

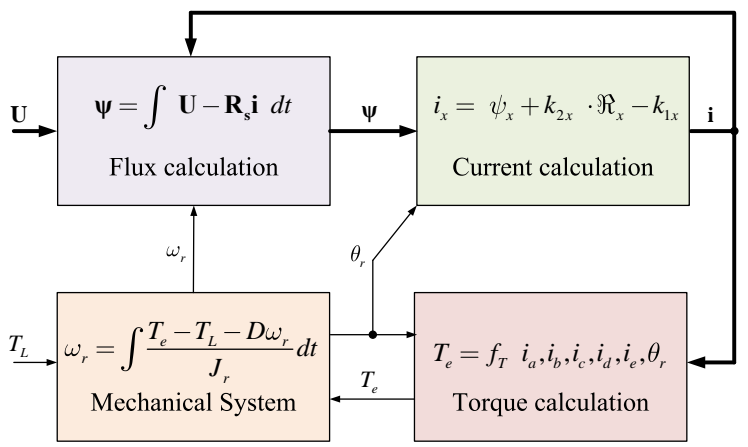

Fig. 8. Proposed PMaSynRM model in vector quantities and inclusion of mechanical subsystem.

In Fig. 6 the flux map of the $B$-phase is shown and in Fig. 7 its corresponding virtual reluctance map. The electromagnetic torque is interpolated from the LUT extracted by FEA:

$$
T_{e}=f_{T} i_{a}, i_{b}, i_{c}, i_{d}, i_{e}, \theta_{r}
$$

The mechanical system is approximated with a first-order equation:

$$
\omega_{r}=\int \frac{T_{e}-T_{L}-D \omega_{r}}{J_{r}} d t
$$

where $T_{L}$ is the load torque, $J_{r}$ stands for the lumped moment 


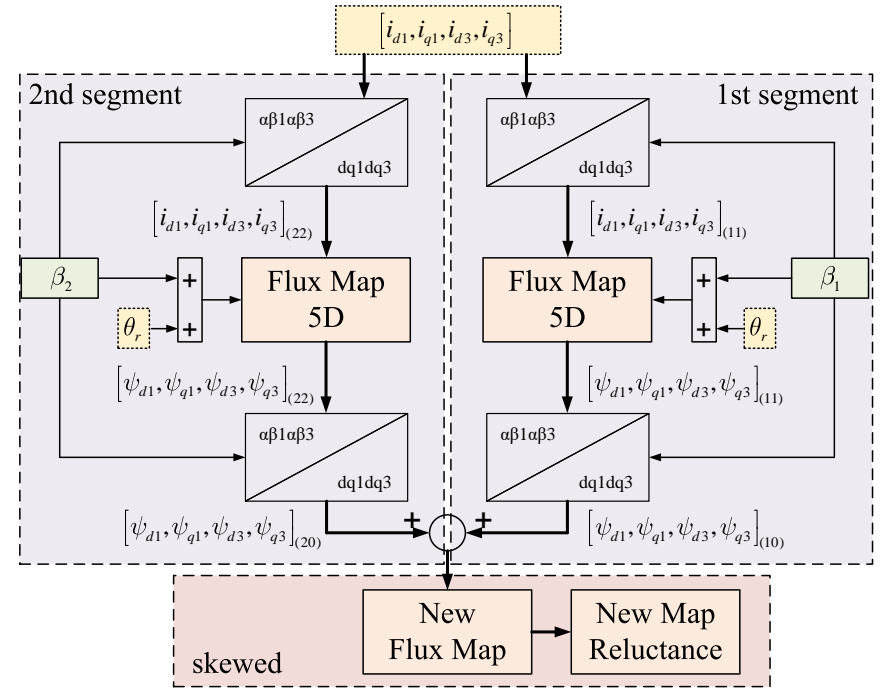

Fig. 9. Proposed algorithm to derive skewed flux and virtual reluctance maps in $d q 1 d q 3$ rotating reference frames.

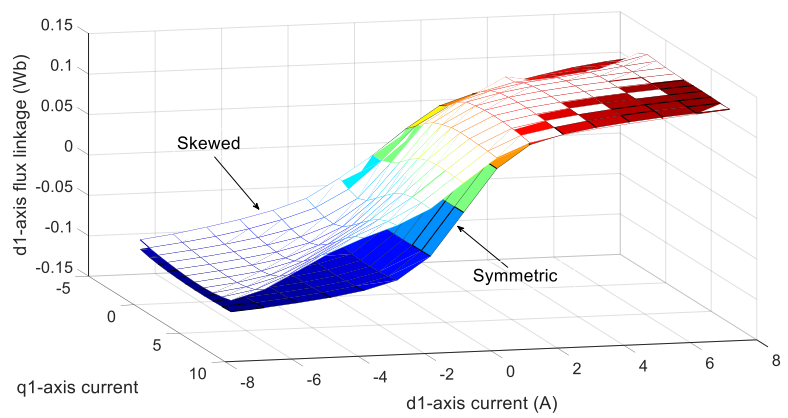

Fig. 10. Original and skewed $d 1$ flux linkage map at $i_{d 3}=0 A, i_{q 3}=0 A$ and rotor angle $=0$ rad.

of inertia at the rotor shaft and $D$ is the friction factor. The resulting model scheme is depicted in Fig. 8.

\section{Discretization}

The software-in-the-loop (SIL) and hardware-in-the-loop (HIL) digital emulation is becoming more attractive due to rapid prototyping advantages of shortening development time, safety, and inexpensive testing of scenarios with fault occurrence in a non-destructive environment [22], [23]. This approach is very helpful for the evaluation of control strategies, fault detection, diagnostic algorithms, and post-fault operation [24].

The previously developed model requires discretization for implementation in the emulation platform. For simplicity, the discrete model in stator phase quantities will be shown in the SIL environment i.e. as a standalone function written in $\mathrm{C}$ language. The integration in Equation (4) to obtain the flux linkage of each phase after forward Euler discretization leads to:

$$
\psi_{x} k+1=\psi_{x} k+T_{s}\left[U_{x} k-R_{s} i_{x} k\right]
$$

where $T_{s}$ stands for the time step, which needs to be small enough to guarantee numerical stability. Then currents are calculated with aid of the virtual reluctances:

$$
i_{x} k+1=\left[\psi_{x} k+1+k_{2 x}\right] \cdot \Re_{x} k-k_{1 x}
$$

The virtual reluctance $\Re_{x} k$ is an inertial element interpolated from the $n$-D map. This interpolation can be solved as $n$ consecutive 1 -D interpolations to adhere to platform computational and resource restrictions such as reported in [24].

\section{STEPPED SKEWING}

The commonly adopted measure to reduce ripple in the generated electromagnetic torque is skewing [25], [26]. By axial skewing, the undesired noise and vibration from torque pulsation can be mitigated. In practice, due to production optimization, the skew in the rotor is advantageous. To avoid additional processes of cutting and machining, the stepped skew is favored.

However, stepped skewing introduces an axial asymmetry in the motor design. Therefore, 2D FEA flux map extraction and its corresponding reluctance map cannot represent the real motor electromagnetic behavior. In [27] the flux map of a threephase IPMSM modeled in a $d q$ synchronous frame was corrected to account for the skewing effect. Hereafter, a methodology to integrate skewing for the five-phase PMasynRM in rotating field and stator phase quantities is shown for posteriori inclusion in virtual reluctances.

\section{A. Skewing in rotating frames}

The flux map is extracted according to (7) from a 2D static FEA scan. Before processing to calculate the virtual reluctance map, the skewing correction is performed. The algorithm for two segment inclusion is depicted in Fig. 9. For each coordinate vector combination $\left[i_{d 1}, i_{a 1}, i_{d 3}, i_{q 3}, \theta_{r}\right]$ in which currents and rotor angle are quantities of the skewed motor, the currents are computed separately for the $1^{\text {st }}$ and $2^{\text {nd }}$ segment using rotator operation of the $1^{\text {st }}$ and $3^{\text {rd }}$ harmonic:

$$
\vec{k}_{d q n(x)}=\vec{k}_{d q n} e^{-n j p \beta_{x}}
$$

where $k$ stands for the space vector quantity, $d$ and $q$ indicate orthogonal axes, $n$ depicts harmonic number, $(x)$ number of the skewing slice and $\beta$ the skewing shift angle of the corresponding segment $(x)$. The flux for each segment is interpolated from the primary axially symmetric flux map with inputs of just transformed currents and adequate rotor angle $\theta_{r}+p \beta_{x}$. Then, the fluxes and rotated back using the transformation of the $1^{\text {st }}$ and $3^{\text {rd }}$ harmonic and summed to give total flux linkage of the two segments skewed motor:

$$
\vec{k}_{d q n}=\vec{k}_{d q n 1} e^{n j p \beta_{1}}+\vec{k}_{d q n} 2 e^{n j p \beta_{2}}
$$




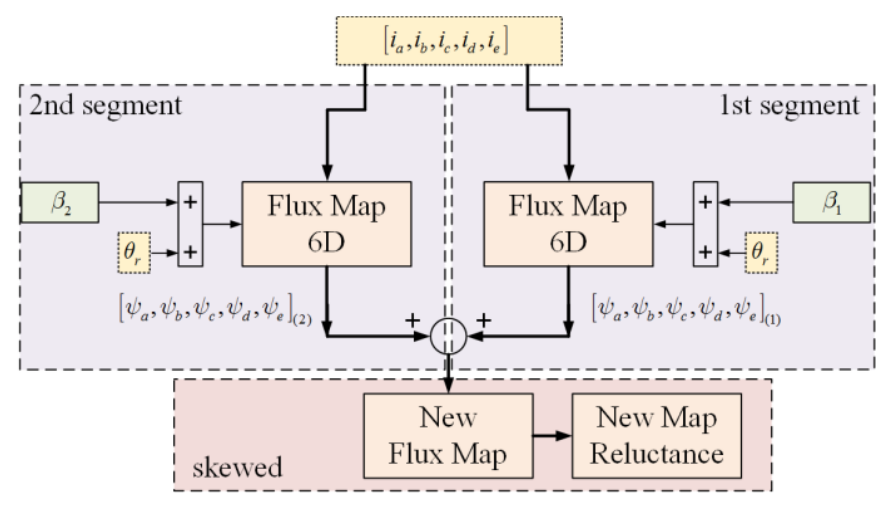

Fig. 11. Proposed calculation of skewed flux map and virtual reluctance map in abcde phase quantities.

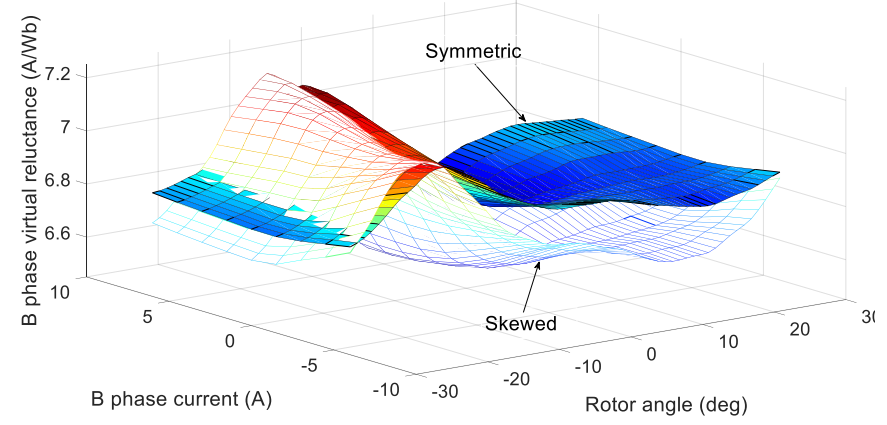

Fig. 12. Original and skewed a-phase virtual reluctance map at $i_{a}=i_{c}=i_{d}=i_{e}=-3 \mathrm{~A}$.

In the next step, the corrected flux map accounting for the skewing effect is used to calculate the virtual reluctance map (12).

\section{B. Skewing in stationary frame}

The flux map is calculated according to (3) in a 2D multistatic axially symmetric FEM analysis. Then, as depicted in Fig. 11, flux linkages for each skewing slice are interpolated from the primary map. The input currents in the natural reference frame bound to phase quantities $i_{a}, i_{b}, i_{c}, i_{d}, i_{e}$ are the same for each slice since the skewing slices are virtually connected in series, however, their associated rotor angles are displaced by $p \beta_{x}$. After interpolation, the flux linkages of the first segment $\psi_{a}, \psi_{b}, \psi_{c}, \psi_{d}, \psi_{e_{1}}$ are summed with the flux linkages of the second segment $\psi_{a}, \psi_{b}, \psi_{c}, \psi_{d}, \psi_{e_{2}}$, and the "skewed" flux map is obtained. Consequently, the virtual reluctance map is calculated according to (14).

\section{Model Validation}

\section{A. FEA axially uniform model}

All 5D rotating field flux and torque maps, and 6D maps in natural phase quantities were numerically obtained via 2D (axially symmetric) static simulations in Altair Flux 2019 using parallel resources. Then, the flux maps were inverted to constitute the state of the art models, and the virtual reluctance

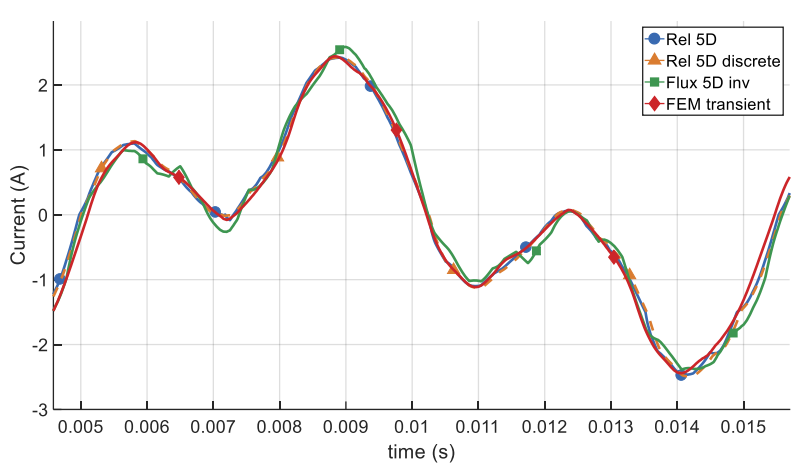

Fig. 13. A-phase current waveform in healthy motor.

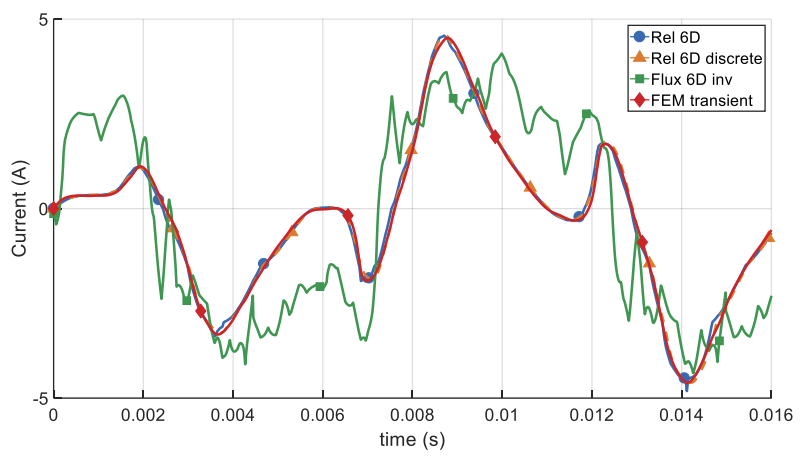

Fig. 14. A-phase current waveform in $B$ and $D$ open phase condition.

maps were established as described in Section III, to construct and evaluate proposed modeling techniques. The time-stepping simulation was built in the Matlab Simulink 2020a environment. In the continuous domain, once current and flux initial conditions are fed, the algebraic loops are easily handled by the Simulink solver. Additionally, the discrete model was written in C language as a standalone block. The motor models were evaluated in a five-phase current control drive simulation with current and rotor position feedback, and ideal five-phase voltage sources controlled by the command voltages from the control block sampled at $10 \mathrm{kHz}$. The simulation step size is $1 \mu \mathrm{s}$. The same algorithm was implemented in coupled Simulink-FEM model to compare with reluctance and inverted flux map. In Fig. 13 and 14, the A-phase current waveform is shown for healthy and BD open phase conditions. Reluctance models exhibit very close to FEM trajectory while in the inverted flux map there is some distortion observed due to residual flux error in the iterative inversion calculation. This type of error is negligible for 2D or 3D maps used for 3-phase motor simulation, nevertheless for a higher number of dimensions it plays a significant role.

\section{B. Experimental with stepped skew}

The skewed VR maps were calculated as described in Section 4. Stepped skewing is not contemplated in the FEM simulation package, the multi-slice approach is available for continuous skew only. Therefore, the skewed model will be compared directly to the experimental results. The test bench with the five-phase prototype drive is shown in Fig. 15. The rotor of the PMaSynRM motor contains two 6 degrees shifted blocks originated from the skewed design. The closed-loop 


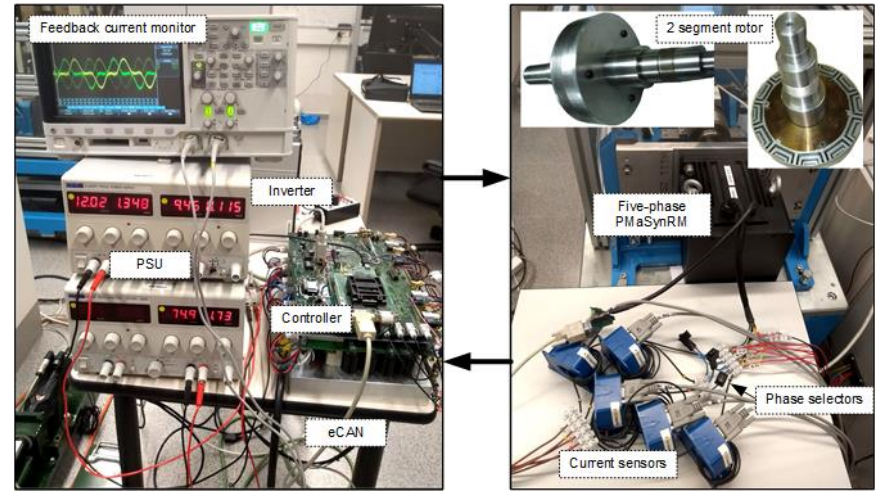

Fig. 15. Experimental setup with skewed five phase PMaSynRM.

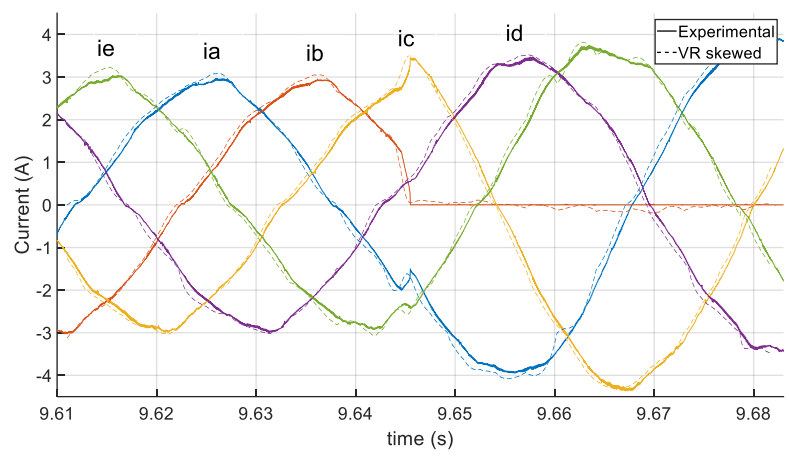

Fig. 16. Current waveform healthy and B-phase open.

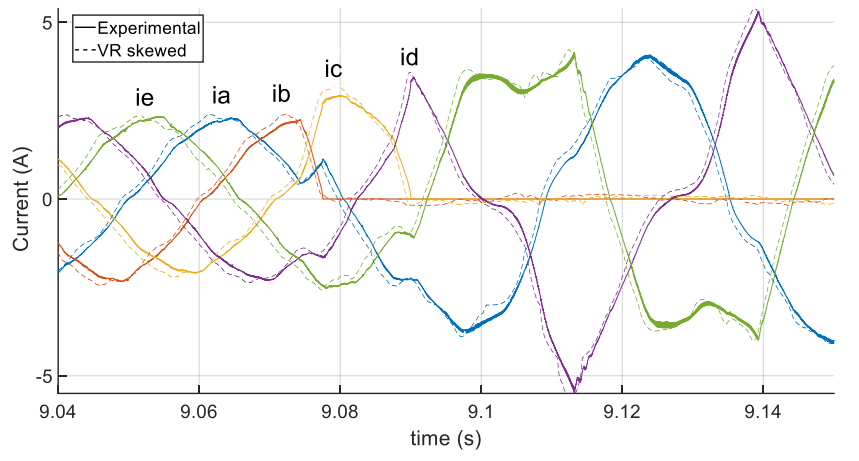

Fig. 17. Current waveform healthy and BC phases open.

current control is implemented in the F28335 digital signal controller with a PWM switching frequency of $10 \mathrm{kHz}$. Five phase currents and voltages are measured by LEM IT $65-\mathrm{S}$ and CV3-1000 sensors and monitored by real-time controller NIcRIO. The voltages pass through the stage of the low pass filter and are saved together with the rotor position. These measured values are then injected into the simulation model based on VRs with skewed adjustment. In such a way, the scenarios from the test setup are evaluated in the time-stepping simulations.

The measured switched current waveform and predicted shape in healthy and B phase open conditions are depicted in Fig. 16. The transition from healthy to open-phase faulty operation is captured. The predicted waveform is in good correlation to the measured one. The comparison of current in BC and BD open phase operation is shown in Fig. 17 and Fig. 18 respectively. In all conditions, the response obtained from

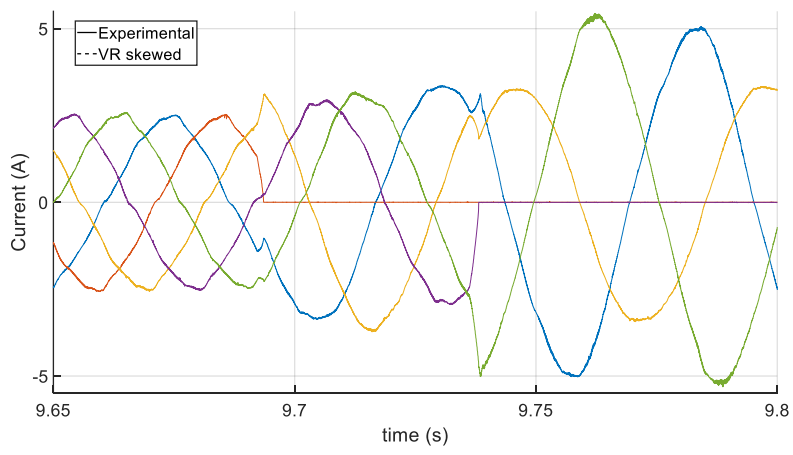

Fig. 18. Current waveform healthy and BD phases open.

the VR model corresponds well to the measured values, although some distortions are present. These can be accounted for the motor mechanical tolerances, physical parameters, and measurements.

\section{CONCLUSION}

A new method for PMaSynRM and IMPSM motor modeling based on the virtual reluctance concept was proposed and developed on a five-phase motor. It comprises nonlinearities carried by inter-phase cross saturation, airgap space harmonics, and axial stepped skew. After flux map identification, the virtual reluctances are derived straight forward without the need for multi-dimensional inversion. FEA and experimental validation have been performed showing the efficacy of the proposed techniques. The proposed technique simplifies accurate electromagnetic modeling and adds to the precision of healthy and faulty drive simulation and development.

\section{ACKNOWLEDGMENT}

This work was supported in part by Spanish Ministry of Economy and Competitiveness under TRA2016-80472-R Research Project and Secretaria d'Universitats i Recerca del Departament d'Empresa i Coneixement de la Generalitat de Catalunya under 2017SGR967.

\section{REFERENCES}

[1] G. Capolino and A. Cavagnino, "New Trends in Electrical Machines Technology-Part II," in IEEE Transactions on Industrial Electronics, vol. 61, no. 9, pp. 4931-4936, Sept. 2014.

[2] G. Pellegrino, A. Vagati, P. Guglielmi and B. Boazzo, "Performance Comparison Between Surface-Mounted and Interior PM Motor Drives for Electric Vehicle Application," in IEEE Transactions on Industrial Electronics, vol. 59, no. 2, pp. 803-811, Feb. 2012.

[3] M. A. Rahman et al., "Advances on Single-Phase Line-Start High Efficiency Interior Permanent Magnet Motors," in IEEE Transactions on Industrial Electronics, vol. 59, no. 3, pp. 1333-1345, March 2012.

[4] G. Sulligoi, A. Vicenzutti and R. Menis, "All-Electric Ship Design: From Electrical Propulsion to Integrated Electrical and Electronic Power Systems," in IEEE Transactions on Transportation Electrification, vol. 2, no. 4, pp. 507-521, Dec. 2016.

[5] A. Echle, A. Neubauer and N. Parspour, "Design and Comparison of Radial Flux and Axial Flux Brushless DC Motors for Power Tool Applications," 2018 XIII International Conference on Electrical Machines (ICEM), Alexandroupoli, Greece, 2018, pp. 125-130.

[6] D. Xu, B. Wang, G. Zhang, G. Wang and Y. Yu, "A review of sensorless control methods for AC motor drives," in CES Transactions on Electrical Machines and Systems, vol. 2, no. 1, pp. 104-115, March 2018.

[7] G. Pellegrino, Th. M. Jahns, N. Bianchi, W. Soong, F. Cupertino, "The Rediscovery of Synchronous Reluctance and Ferrite Permanent Magnet 
Motors," in SpringerBriefs in Electrical and Computer Engineering, Springer 2016, ISBN 978-3-319-32202-5.

[8] A. Shanshal, K. Hoang and K. Atallah, "High-Performance Ferrite Permanent Magnet Brushless Machines," in IEEE Transactions on Magnetics, vol. 55, no. 7, pp. 1-4, July 2019.

[9] Q. Ma, A. El-Refaie and B. Lequesne, "Low-Cost Interior Permanent Magnet Machine With Multiple Magnet Types," in IEEE Transactions on Industry Applications, vol. 56, no. 2, pp. 1452-1463, March-April 2020.

[10] E. E. Ward and H. Härer, "Preliminary investigation of an invertor-fed 5phase induction motor," in Proceedings of the Institution of Electrical Engineers, vol. 116, no. 6, pp. 980-984, June 1969.

[11] L. Parsa and H. A. Toliyat, "Five-phase permanent-magnet motor drives," in IEEE Transactions on Industry Applications, vol. 41, no. 1, pp. 30-37, Jan.-Feb. 2005, doi: 10.1109/TIA.2004.841021.

[12] G. Liu, L. Qu, W. Zhao, Q. Chen and Y. Xie, "Comparison of Two SVPWM Control Strategies of Five-Phase Fault-Tolerant PermanentMagnet Motor," in IEEE Transactions on Power Electronics, vol. 31, no. 9, pp. 6621-6630, Sept. 2016.

[13] S. Wang, J. Kang, M. Degano, A. Galassini and C. Gerada, "An Accurate Wide-Speed Range Control Method of IPMSM Considering Resistive Voltage Drop and Magnetic Saturation," in IEEE Transactions on Industrial Electronics, vol. 67, no. 4, pp. 2630-2641, April 2020.

[14] B. Stumberger, G. Stumberger, D. Dolinar, A. Hamler and M. Trlep, "Evaluation of saturation and cross-magnetization effects in interior permanent-magnet synchronous motor," in IEEE Transactions on Industry Applications, vol. 39, no. 5, pp. 1264-1271, Sept.-Oct. 2003.

[15] M. Boesing, M. Niessen, T. Lange and R. De Doncker, "Modeling spatial harmonics and switching frequencies in PM synchronous machines and their electromagnetic forces," 2012 XXth International Conference on Electrical Machines, Marseille, France, 2012, pp. 3001-3007.

[16] L. Quéval and H. Ohsaki, "Nonlinear abc-Model for Electrical Machines Using N-D Lookup Tables," in IEEE Transactions on Energy Conversion, vol. 30, no. 1, pp. 316-322, March 2015.

[17] X. Chen, J. Wang, B. Sen, P. Lazari and T. Sun, "A High-Fidelity and Computationally Efficient Model for Interior Permanent-Magnet Machines Considering the Magnetic Saturation, Spatial Harmonics, and Iron Loss Effect," in IEEE Transactions on Industrial Electronics, vol. 62, no. 7, pp. 4044-4055, July 2015.

[18] B. Sen, J. Wang and P. Lazari, "A High-Fidelity Computationally Efficient Transient Model of Interior Permanent-Magnet Machine With Stator Turn Fault," in IEEE Transactions on Industrial Electronics, vol. 63, no. 2, pp. 773-783, Feb. 2016.

[19] T. Michalski, F. Acosta-Cambranis, L. Romeral and J. Zaragoza, "Multiphase PMSM and PMaSynRM Flux Map Model with Space Harmonics and Multiple Plane Cross Harmonic Saturation," IECON 2019 - 45th Annual Conference of the IEEE Industrial Electronics Society, Lisbon, Portugal, 2019, pp. 1210-1215.

[20] Hyung-Min Ryu, Jang-Hwan Kim and Seung-Ki Sul, "Analysis of multiphase space vector pulse-width modulation based on multiple d-q spaces concept," in IEEE Transactions on Power Electronics, vol. 20, no. 6, pp. 1364-1371, Nov. 2005.

[21] E. Levi, "Multiphase Electric Machines for Variable-Speed Applications," in IEEE Transactions on Industrial Electronics, vol. 55, no. 5, pp. 1893-1909, May 2008.

[22] G. Luo, R. Zhang, Z. Chen, W. Tu, S. Zhang and R. Kennel, "A Novel Nonlinear Modeling Method for Permanent-Magnet Synchronous Motors," in IEEE Transactions on Industrial Electronics, vol. 63, no. 10, pp. 6490-6498, Oct. 2016.

[23] N. Roshandel Tavana and V. Dinavahi, "A General Framework for FPGA-Based Real-Time Emulation of Electrical Machines for HIL Applications," in IEEE Transactions on Industrial Electronics, vol. 62, no. 4, pp. 2041-2053, April 2015, doi: 10.1109/TIE.2014.2361314

[24] F. Alvarez-Gonzalez, A. Griffo, B. Sen and J. Wang, "Real-Time Hardware-in-the-Loop Simulation of Permanent-Magnet Synchronous Motor Drives Under Stator Faults," in IEEE Transactions on Industrial Electronics, vol. 64, no. 9, pp. 6960-6969, Sept. 2017.

[25] L. Parsa and L. Hao, "Interior Permanent Magnet Motors With Reduced Torque Pulsation," in IEEE Transactions on Industrial Electronics, vol. 55, no. 2, pp. 602-609, Feb. 2008.

[26] R. Islam, I. Husain, A. Fardoun and K. McLaughlin, "Permanent-Magnet Synchronous Motor Magnet Designs With Skewing for Torque Ripple and Cogging Torque Reduction," in IEEE Transactions on Industry Applications, vol. 45, no. 1, pp. 152-160, Jan.-feb. 2009.

[27] P. Lazari, B. Sen, J. Wang and X. Chen, "Accurate $\backslash(d \backslash)-\backslash(\{q\} \backslash)$ Axis Modeling of Synchronous Machines With Skew Accounting for
Saturation," in IEEE Transactions on Magnetics, vol. 50, no. 11, pp. 1-4, Nov. 2014, Art no. 8105704.

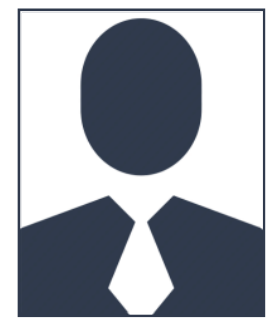

Tomasz Dobromir Michalski (M'16) received the M.S. degree in electrical engineering from the Warsaw University of Technology (WUT), Warsaw, Poland, in 2011. He is working towards the Ph.D. degree in the Motion Control and Industrial Applications Center, Universitat Politecnica de Catalunya, Barcelona, Spain.

His research interests include modeling design and implementation of variable-speed drives, sensorless control, multi-phase motors, conversion, and DSP applications. FEM and lumped parameter modeling, power

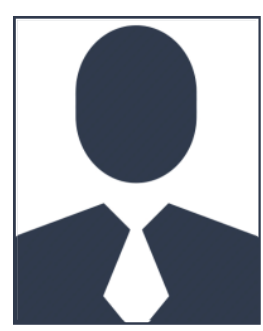

Jose Luis Romeral Martinez (M'98) received the M.S. degree in electrical engineering and the Ph.D. degree from Universitat Politecnica de Catalunya (UPC), Barcelona, Spain, in 1985 and 1995 respectively.

In 1988, he joined the Electronic Engineering Department, UPC, where he is currently an Associate Professor and the Director of the Motion control and Industrial Control Group, the major research activities of which concern induction and permanent-magnet motor drives, enhanced efficiency drives, fault detection and diagnosis of electrical motor drives, and improvement of educational tools. He has developed and taught post-graduate courses on programmable logic controllers, electrical drives and motion control, and sensors and actuators.

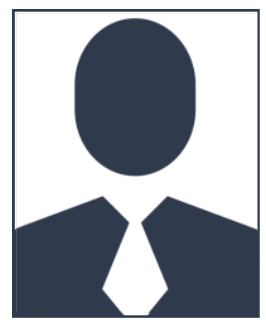

Third C. Author3 (M'99-SM'04-F'09) was born in City, Country. He received the M. and SM. and $F$. degrees in electrical engineering from University of City, Country in 1999, 2004 and 2009 respectively.

The second paragraph uses the pronoun of the person (he or she) and not the author's last name. It lists military and work experience, including similar information to the previous author, including military, work experience, and other jobs.

The third paragraph begins with the author's title and last name (e.g., Dr. Smith, Prof. Jones, Mr. Kajor, Ms. Hunter), including similar information to the previous author, including the list of any awards and work for IEEE committees and publications. The photograph is placed at the top left of the biography. Personal hobbies will be deleted from the biography. 